\title{
Cómo acabar con la pobreza que es lo que funciona cuando los métodos tradicionales fracasan
}

\author{
How to end poverty what works when traditional methods fail \\ Pedro Alfonso Ramos Sánchez ${ }^{a}$, Noemi Vega Lugo ${ }^{b}$
}

\begin{abstract}
:
There are about eight hundred million people living with a dollar a day worldwide. The author focuses on the fact that the same people who suffer from poverty can generate novel and simple opportunities to generate change. Combating poverty implies, speaking and listening to those involved and understanding their context. The methodology is narrated through the story of Krishna Bahadur Thapa of Nepal who emerges from poverty using Polak methodologies.
\end{abstract}

Keywords:

Fight against poverty, neighborhood, green revolution

Resumen:

En el mundo hay cerca de ochocientos millones de personas que viven con un dólar al día. El autor se centra en que las mismas personas que sufren de pobreza pueden generar oportunidades novedosas y simples para generar cambios. Combatir la pobreza implica, hablar y escuchar a los involucrados y entender su contexto. La metodología es narrada mediante la historia de Krishna Bahadur Thapa de Nepal que sale de la pobreza utilizando las metodologías de Polak.

\section{Palabras Clave:}

Combate a la pobreza, barriadas, revolución verde

\section{Introducción}

Actualmente en el mundo hay cerca de ochocientos millones de personas que viven con un dólar al día, la pregunta clave es si ¿existen estrategias creativas que permitan alcanzar la prosperidad?

El producto del trabajo de Paul Polak en la empresa "Empresas Internacionales de Desarrollo", con sus siglas en inglés (IDE), ofrece una respuesta. El autor se centra en que las propias personas que sufren de pobreza pueden generar oportunidades novedosas y simples capaces de generar cambios. Polak mira a los pobres como clientes o usuarios y genera productos que les ayudan a mejorar sus condiciones de vida, como es el caso de una bomba para extracción de agua, resolviendo problemas de desabasto de agua en Bangladesh, donde el autor emprende negocios que permiten desde un punto de vista mejorar en lo social y económico.

Reseña
Las preguntas básicas de Polak son: ¿Qué vuelve pobres a los pobres? Y ¿qué pueden hacer con su pobreza? La respuesta a estas incógnitas son el hilo conductor en el trabajo del autor que proyecta un enfoque de combate a la pobreza desde una óptica inspiradora y esperanzadora en vez de discursos teóricos y perspectivas grises del tema pobreza.

Es un libro publicado en 2008 con 234 páginas y doce capítulos donde se narra además de importantes conceptos la vida de Krishna Bahadur Thapa de Nepal que superó la pobreza a través de las técnicas de Polak, para este autor, aprender a hacer lo simple y obvio no siempre es fácil de hacer, él propone la creación de mercados robustos que se fundamentan en ideas de cómo producir y vender cultivos de alto valor intensivo en mano de obra, como frutos y verduras fuera de temporada, venderlos en mercados óptimos con una ganancia adecuada.

El salir de la pobreza no debe de ser considerado como imposible sino más bien una meta que pueda alcanzarse en algunos meses, ofrecer soluciones prácticas para combatir la pobreza depende de identificar el problema

\footnotetext{
${ }^{a}$ Doctor en el Área Académica de Turismo, Instituto de Ciencias Económico Administrativas de la Universidad Autónoma del Estado de Hidalgo, pedro_ramos3944@uaeh.edu.mx

b Maestra en el Área Académica de Turismo, Instituto de Ciencias Económico Administrativas de la Universidad Autónoma del Estado de Hidalgo,noemivl@uaeh.reduaeh.mx
} 
estando presente donde está la acción, hablar y escuchar a las personas en sus problemáticas, identificando el contexto del problema, hay que pensar y actuar en grande, reducir el problema a sus elementos básicos y hacer primero lo obvio identificando las debilidades, aprovechar lo ya inventado y usarlo, es importante que se generen impactos que se puedan medir y que las propuestas lleguen al menos a un millón de personas y que los impactos deben sean capaces de mejorar su forma de vida.

Polak considera tres grandes mitos de la erradicación de la pobreza, como la idea de que se sale de la pobreza con donativos, contrario a lo que se piensa si no se controla bien que es lo que se dona, puede tener un efecto contrario en el mercado o en los usuarios, otra idea es que el crecimiento económico per cápita terminará con la pobreza, la propuesta del autor se centra en generar crecimiento económico y prosperidad económica en microgranjas remotas y barriadas urbanas, para que este crecimiento sea homogéneo y no sólo ocurra donde se presenta el crecimiento industrial y se deja de lado a los pobres. Por último el enfoque de que las grandes empresas terminarán con la pobreza es muy subjetivo, pues aunque las multinacionales son una buena opción de aumento de empleos, deberían de fomentar hacer cambios para tener un impacto positivo en la vida de los muy pobres y esto no siempre es atendido, lo que debería de hacerse es a través de modelos de negocios económicamente sustentables, atender a clientes pobres que viven con menos de un dólar al día llegando con precios accesibles con un precio de mercado justo no subsidiado y que los impactos en la pobreza que presenten puedan medirse.

El éxito en el combate a la pobreza está primero en una revolución mental y la puesta en práctica por parte de la comunidad del desarrollo, la comunidad de negocios y los pobres mismos trabajando unidos con la mira en incrementar los ingresos, esto equivale según el autor a que al menos quinientos millones de familias que hoy sobreviven con menos de un dólar al día puedan hallar formas prácticas de acabar con su pobreza en una generación.

Para lograr lo anterior todo debe comenzar por ganar más, los principales problemas para atacar la pobreza se centran en la falta de poder para atender cuestiones de salud, educación deficiente, la ausencia de infraestructura de transporte siendo estas causas de fondo. Para cruzar estas brechas el paso más importante está en que las personas puedan generar más ingresos, esto permitirá mejorar la forma en que tomen decisiones y seleccionar qué causa de fondo de la pobreza van a atacar. Siendo el modo más eficaz dotar de vida y rentabilidad las empresas de base que ellos emprendan, el libro pone el ejemplo de las barriadas urbanas y micro granjas en áreas rurales.

El $90 \%$ de los diseñadores está ocupado en vender productos o soluciones al $10 \%$ de los más ricos clientes del mundo. Es necesaria una revolución en el trabajo de los diseñadores y que implique que los beneficios lleguen al otro $90 \%$. Diseñar productos atractivos para clientes pobres requiere de una revolución en el proceso de diseño, sin embargo esta revolución ya está en marcha.
En 2007 el Cooper-Hewitt Design Museum de Nueva York, uno de los museos de la Smithsonian Institutión, abrió la exposición "Design for the Other 90 Percent" donde se presentaron 36 diseños para pobres de todo el mundo, donde destacaron: bombas de pedal sistemas de goteo de bajo costo, sistemas de purificación de agua de bajo costo y una tecnología que permite a empresas rurales convertir hojas de caña de azúcar en briquetas de carbón comercializables.

Es muy importante enseñar a los pequeños agricultores a no solo producir para su consumo y venta por temporada sino a optimizar la forma en la que producen, ya que por costumbre siguen utilizando las mismas técnicas y en este tiempo es posible aumentar el rendimiento de los cultivos adoptando las estrategias de revolución verde, que incrementa la oferta local de alimentos, aumenta los ingresos con producción excedente y para el autoconsumo. La revolución verde aumenta drásticamente la producción de alimentos mitigando el hambre y la pobreza, estas técnicas son muy empleadas en China y en India donde la aplicación de estas tecnologías ha permitido que estos países exporten granos.

La irrigación de bajo costo para las microgranjas es la base para mejorar su producción agrícola pues basta con dos cubetas y media al día para cultivar un huerto pequeño con instrumentos de goteo, la idea es utilizar equipo de tres dólares y poder ganar 9 dólares vendiendo las verduras excedentes. Las herramientas de irrigación pueden clasificarse en tecnologías de extracción, almacenamiento y distribución de agua. Para la extracción pueden usarse bombas de pedal, bombas de pedal y arandela y micro bombas de diésel. En el almacenamiento de agua se pueden usar técnicas bajo la tierra y en la superficie, construyendo estanques y tanques de bajo costo, para la distribución del agua puede ser goteo de bajo costo y sistema de aspersores de bajo costo. A pesar de que el agua es lo más importante también lo es saber qué es lo que se va a cultivar pues lo que se siembre debe de ser comercializable y vendido con ganancias. Los cambios que las empresas agrícolas pueden dar mediante el uso de micro granjas con rotación de cultivos y micro goteo pudo significar para una familia nepalesa pasar de cultivos de sobrevivencia a cultivos que reportaron ganancias excedentes permitiendo un cambio de vida mejorando significativamente su poder adquisitivo y nivel socioeconómico.

Las personas que viven con menos de un dólar al día y los productos que ofrecen también participan en los mercados que son muy competidos y que implican que se persiga mejorar los productos en su calidad y procesos de producción, tratándose de cultivos, el agua es un elemento importante pues afecta drásticamente las utilidades, la mayoría de estos mercados hace difícil que se puedan obtener las ganancias adecuadas con los productos que producen. A pesar de que los líderes visionarios son capaces de crear mercados donde no los hay, en los países subdesarrollados la ineficiencia de los mercados tiene sus causas en múltiples factores como la falta de esperanza, mala visión, ausencia de protección a la propiedad intelectual, subsidios, la corrupción, el 
aislamiento por la lejanía, la falta de información y acceso deficiente a créditos. El autor busca la solución a estas problemáticas en encontrar mercados para clientes pobres, menciona que cientos de mercados de diversos tipos están a la espera de ser descubiertos. El mismo ofrece soluciones para los mercados como: reclutar fabricantes de pequeña escala, reclutar distribuidores rurales, capacitar a perforadores de pozos, abrir acceso a microcréditos y poner en marcha iniciativas de mercadotecnia por mencionar las principales.

Los habitantes de barriadas pueden tener mayor acceso a empleos e ingresos haciendo y comercializando productos de alto valor, intensivos en mano de obra, al igual que las micro granjas. Un ejemplo importante es el caso de Dharabvi (una población del área central de Bombay, India,) en donde una encuesta realizada en 1986 por la National Slum Dewellers Feredation identificó mil cuarenta y cuatro operaciones manufactureras, sin contar con muchas pequeñas operaciones en casas y buhardillas, estos datos indican que existe una gran mano de obra y personas dispuestas a trabajar en estos espacios. El grupo de trabajo para la mejora de la vida de los habitantes de barriadas de la ONU, dirige su atención a temas como mejoras en las viviendas, inseguridad, tenencia de agua y drenaje de las barriadas así como los servicios de educación y salud, sin embargo no hay mucha información en materia de modelos de negocio, mercadotecnia y rentabilidad para las empresas de base que son muy importantes para la supervivencia de estos grupos sociales. Ampliar mercados productos y servicios y aumentar la rentabilidad es el reto para las empresas de barriadas.

\section{Conclusiones}

El autor considera que acabar con la pobreza es el primer paso y el más importante para restaurar el equilibrio natural del planeta, las prioridades pueden ser diferentes, sin embargo el reto para los próximos cincuenta años son sin duda el cambio climático, las emisiones de carbono, la pérdida de biodiversidad epidemias globales y acceso a la educación.

Hablar de desarrollo tiene que ver con personas dispuestas a generar estos cambios siendo el caso de los actores y sus acciones para terminar con la pobreza y todos tienen que participar siendo el caso de las multinacionales, universidades, institutos de investigación agrícola de riego y los mismos pobres, que tendrán que adoptar nuevas formas de pensamiento para acabar con ella. El libro ofrece ideas prácticas para que cada actor tenga acciones para combatir la pobreza.

Los conceptos y aplicaciones prácticas son narrados a partir de contar la historia de Krishna Bahadur Thapa originario de Nepal que logra grandes avances para salir de la pobreza junto con su familia, utilizando las metodologías de Polak. Krishna Bahadur aprovecha oportunidades como mejorar la educación y alimentación de su familia así como ampliar la producción, incrementando año con año sus ingresos, terreno y fuentes de ingresos, superando ser una familia que vivía con menos de un dólar al día a una familia con oportunidades y condiciones de vida mejoradas, dejando atrás la pobreza.

\section{Referencias}

[1] Polak, P. (2008). Cómo Acabar Con la Pobreza: Qué Es Lo Que Funciona Cuando Los Métodos Tradicionales Fracasan. Editorial Océano de México. 